\section{Original article}

\title{
Prevalence and risk factors of HSV-1 and HSV-2 antibodies in European HIV infected women
}

B H B van Benthem, J Spaargaren, J A R van den Hoek, J Merks, R A Coutinho, M Prins, and the European Study on the Natural History of HIV Infection in Women

Objectives: To investigate the prevalence and risk factors of HSV-1 and HSV-2 antibodies in HIV infected women and the association between recurrent genital ulcerations and HIV disease progression in HSV-2 positive women.

Methods: The presence of HSV antibodies was tested in 276 of the 487 women participating in a European cohort study of HIV infected women. Prevalence rate ratios described the association between HSV infection and its risk factors, using log binomial regression. Generalised estimating equations (GEE) analysis was performed to determine the impact of markers of HIV disease progression on recurrent genital ulcerations.

Results: The prevalence of HSV-1 and HSV-2 antibodies was 76\% (95\% confidence interval (95\% CI): $71-81)$ and $42 \%$ (95\% CI: 36-50); 30\% (95\% CI: 24-35) of the women had antibodies against both HSV-1 and HSV-2. The prevalence of HSV-1 was 86\% (95\% CI: 80-92) in southern Europe compared with 69\% (95\% CI: 57-79) and 67\% (95\% CI: 55-77) in central and northern Europe $(p=0.002)$. This geographical variation remained after adjustment for other risk factors. An increasing number of years of sexual activity $(\mathrm{p}=0.0002)$ and a history of prostitution $(\mathrm{p}=0.0001)$ were independently associated with HSV-2 prevalence. In HSV-2 positive women, symptomatic cases of HSV infection were minimal, but increased with decreasing CD4 count.

Conclusion: In HIV infected women, the prevalence of HSV antibodies is high and symptomatic cases of HSV infection are minimal, but increase with decreasing CD4 count. HSV-2 but not HSV-1 was related to sexual behaviour (that is, a history of prostitution and the number of sexually active years) in this group of HIV infected women.

(Sex Transm Inf 2001;77:120-124)

Keywords: herpes simplex viruses; genital ulcerations; HIV infection; women; Europe

\section{Introduction}

Infection with herpes simplex viruses (HSV) is very common worldwide. In European countries, the estimated prevalence of HSV-1, determined by means of antibody measurements, varies between $60 \%$ and $90 \%$ in the general population, whereas the prevalence of HSV-2 ranges from $8 \%$ in pregnant women to $50 \%$ in homosexual men. ${ }^{1}$ Transmission of HSV-2 is more efficient from men to women than vice versa. ${ }^{2}{ }^{3}$ Usually, HSV-1 infection occurs in childhood, causing mainly oro-labial lesions, but it can occur with sexual transmission, causing genital herpes. ${ }^{4}{ }^{5} \mathrm{HSV}-2$ infection, the major cause of genital herpes, is almost always sexually transmitted. After primary infection, both types remain latently present in the body and lead to the production of lifelong antibodies. A previous HSV-1 infection appears to provide a degree of protection against primary genital HSV-2 infection and its severity. $^{23}$

The presence of genital herpes increases the risk for transmission of HIV. ${ }^{6}$ Only a minority of HSV-2 infected people develop clinical symptoms of HSV-2 infection and asymptomatic HSV-2 shedding is more common in people co-infected with HIV than in HIV uninfected people..$^{8-11}$ These findings indicate that a large proportion of HSV-2 infected individuals are unaware of their HSV-2 infection and are at risk of transmitting the agent. Risk factors for HSV-1 and HSV-2 prevalence in HIV infected people have not yet been studied. Therefore, the objectives of our study were to determine the prevalence and risk factors of HSV-1 and HSV-2 in a cohort of European women with HIV infection of known duration. Furthermore, we assessed the relation between HIV disease progression and the recurrence of genital ulcerations in HSV-2 infected women.

\section{Methods}

STUDY POPULATION

The European Study on the Natural History of HIV Infection in Women involves a prospective cohort of HIV infected women with a known interval of HIV seroconversion, as detailed elsewhere. ${ }^{12}$ Since 1993, 487 women from 31 centres in 12 European countries have been included. Follow up visits are scheduled every 6 months. At each visit, a standardised questionnaire is used to record various sociodemographic and sexual characteristics and a clinical examination, including a gynaecological examination, is performed. During each visit immunological (for example, CD4 count) and virological (for example, HIV-RNA levels) markers are determined. In 276 of the 487 women ( $57 \%$ ), extra blood samples were taken at the first visit and during follow up and stored in the central repository of the European women's study. Of these blood samples, we used the first available sample drawn in each case for the 
determination of HSV antibodies. The stored sample had been obtained at study entry in 138 women $(50 \%)$; it was taken within 10 months of study entry in an additional 69 women $(25 \%)$. Samples were obtained for all women within 4 years after study entry. Differences in risk factors (mentioned below) for the presence of HSV antibodies between women with and without a blood sample were tested and it appeared that these groups only differed for geographic region, place of recruitment, mode of HIV transmission, and age at first vaginal intercourse.

LABORATORY METHODS

The first available blood sample for each woman was tested for specific antibodies against HSV-1 and HSV-2. Analysis of HSV antibodies was performed with a commercial enzyme immunoassay (EIA, Gull Laboratories, Germany). ${ }^{13}$ An extinction ratio (compared with a control) above 1.5 was defined as seropositive, less than 0.8 as seronegative, and between 0.8 and 1.5 as intermediate. Samples with extinction ratios in the intermediate zone for either HSV-1 $(n=34)$ or HSV-2 $(n=38)$ were retested with a rapid immunoblot assay (RIBA, Chiron Corporation, CA, USA) used according to the manufacturer's instructions. ${ }^{14}$ Both tests were evaluated by our research group and were found to be suitable for epidemiological studies. ${ }^{15}$ Of the 34 intermediate HSV-1 samples, 25 were positive and nine were negative for HSV-1 antibodies with immuno blot. Of the 38 samples intermediate for HSV-2, 35 were reactive, and three turned out to be non-reactive to specific HSV-2 antigens.

RISK FACTORS

Various sociodemographic and sexual characteristics as well as methodological risk factors were assessed by means of the questionnaire and were evaluated as risk factors for the prevalence of HSV-1 and HSV-2 antibodies. Sociodemographic risk factors included mode of HIV transmission (heterosexual intercourse, injecting drug use, other), geographic region, age at sampling, continent of birth (Europe $v$ non-Europe), marital status, and age at end of education. Geographic region (that is, region where the women live) was divided into three categories: south (Greece, Italy, Portugal, Spain), central (Belgium, France, Netherlands, Switzerland), and north (Denmark, Finland, Norway, Sweden). Sexual behaviour at the time the blood sample was measured in terms of history of STD, history of prostitution, the number of past sexual partners (that is, a person with whom they had sexual intercourse), the number of years of sexual activity, and age at first vaginal intercourse. The following methodological risk factors were examined: lag time between seroconversion and study entry, setting of the centre, year of the first HIV positive test, and year when the blood sample was drawn. All risk factors were categorised based on the median, tertiles, or quartiles, except the number of past sexual partners, which had been categorised in the questionnaire. Time dependent categorised risk factors
Table 1 Prevalence of HSV-1 and HSV-2 antibodies in HIV infected women registered in the European Women Study

\begin{tabular}{llll}
\hline \multicolumn{4}{l}{ HSV-2 antibodies } \\
\cline { 2 - 4 } & $\begin{array}{l}\text { Negative } \\
\text { No (\%) }\end{array}$ & $\begin{array}{l}\text { Positive } \\
\text { No (\%) }\end{array}$ & $\begin{array}{l}\text { Total } \\
\text { No (\%) }\end{array}$ \\
\hline $\begin{array}{l}\text { HSV-1 antibodies } \\
\text { Negative }\end{array}$ & $32(12)$ & $34(12)$ & $66(24)$ \\
$\begin{array}{l}\text { Positive } \\
\text { Total }\end{array}$ & $128(46)$ & $82(30)$ & $210(76)$ \\
\hline
\end{tabular}

related to HIV disease progression were evaluated as risk factors of recurrence of genital ulcerations. These risk factors were CD4 counts and HIV-RNA levels. To ensure the right direction of cause and effect, $\mathrm{CD} 4$ counts and HIV-RNA levels were used from the visit preceding assessment of genital ulcerations.

STATISTICAL ANALYSES

When the prevalence of an outcome is high, odds ratios can be misleading if they are interpreted as relative risks. ${ }^{16-18}$ Because the prevalence of HSV-1 and HSV-2 was high in the present study, prevalence rate ratios instead of odds ratios were used to describe the association between HSV infection and its risk factors. The analyses were done with the GENMOD procedure in SAS, using a log binomial regression model in which the log transformed prevalence is a linear function of the risk factors. ${ }^{19}$ Risk factors significantly associated $(p<0.05)$ with the prevalence of HSV antibodies were selected for the multivariable analyses, using a forward procedure. In multivariable analyses, we tested interactions between risk factors in the final model and confounding.

The effect of HIV-RNA levels (available for 194 of 276 women) and CD4 count on the recurrence of genital ulcers in HSV-2 positive women was measured using a logistic regression model for repeated measurements. This generalised estimating equation method (GEE) corrects for correlation between measurements within the same individual. We applied a correlation structure that assumes an equal correlation between all measurements of one woman. ${ }^{20}$

\section{Results}

Among 276 HIV infected women, the prevalence of HSV-1 antibodies was $76 \%$ (95\% CI (95\% CI): $71.1-81.1$ ), and the prevalence of HSV-2 antibodies was $42 \%$ (95\% CI: $36.2-$ 47.9) (table 1). The prevalence of the presence of both HSV-1 and HSV-2 antibodies was 30\% (95\% CI: 24.3-35.1). At the time of sampling, only $25 \%$ of the HSV-2 infected women and $13 \%$ of the HSV-1 infected women reported a history of genital herpes. Furthermore, $62 \%$ of the women who reported a history of genital herpes were HSV-2 positive, and $11 \%$ of the all $\mathrm{HSV}-2$ positive women received antiviral HSV treatment at least once.

The prevalence and prevalence rate ratios of HSV-1 infection by geographic region are presented in table 2. Of all subjects living in southern Europe 86\% were infected with 
Table 2 Risk factor independently associated with the presence of HSV-1 antibodies among 276 women registered in the European Women Study

\begin{tabular}{lllll}
\hline & $\begin{array}{c}\text { Prevalence } \\
(\%)\end{array}$ & \multicolumn{2}{l}{ HSV-1 infection } & \\
& & $P R^{\star}$ & $95 \% C I^{\star}$ & p Value \\
\hline Geographical region & & & & \\
South & 86 & 1.00 & & 0.0017 \\
Central & 69 & 0.80 & $0.67-0.94$ & \\
North & 67 & 0.78 & $0.64-0.91$ & \\
\hline
\end{tabular}

$\star \mathrm{PR}=$ prevalence rate $\mathrm{CI}=$ confidence interval estimated with $\log$ binomial regression analyses.

HSV-1 compared with $69 \%$ and $67 \%$ of all those living in central and northern Europe, respectively. This difference was statistically significant $(p=0.002)$, even after adjustment for other risk factors. The presence HSV-1 antibodies was not related to sexual behaviour in this group of European HIV infected women, not even when the analysis was restricted to women under the age of 30 years. All other risk factors, including continent of birth, were not significantly associated with HSV-1 prevalence or confounded the association between HSV-1 infection and geographic region.

The results of univariable and multivariable analyses of HSV-2 infection are shown in table 3. In univariable analysis, the prevalence of HSV-2 antibodies was associated with the mode of HIV transmission, geographic region, age, and sexual behaviour. The presence of antibodies for HSV-1 decreased the likelihood of HSV-2 infection, although not significantly (prevalence rate ratio (PR): 0.76, 95\% CI: $0.57-1.03)$. Women with a history of STD or prostitution had a higher risk of HSV-2 infection than women without such histories. In univariable analysis, the prevalence of HSV-2 antibodies increased significantly with increases in number of sexual partners and number of years of sexual activity. After adjustment for sexual behaviour, the effects of mode of HIV transmission, geographic region and age were no longer significant. In multivariable
Table 4 Clinically diagnosed genital ulcerations stratified by markers of HIV disease progression in HSV-2 positive women registered in the European Women Study

\begin{tabular}{|c|c|c|c|}
\hline & \multicolumn{3}{|c|}{ HSV-2 positive } \\
\hline & No $(\%)^{\star}$ & ORt & $95 \% \mathrm{CI} \dagger$ \\
\hline \multicolumn{4}{|l|}{ CD4 count $\left(\times 10^{6} / 1\right)$} \\
\hline$\geqslant 200$ & $7(2)$ & 1.00 & \\
\hline$<200$ & $8(8)$ & 4.87 & $1.53-15.5$ \\
\hline \multicolumn{4}{|c|}{ HIV-RNA levels (copies/ml) } \\
\hline$\leqslant 1000$ & $1(1)$ & 1.00 & \\
\hline $1001-100000$ & $3(3)$ & 1.48 & $0.47-4.70$ \\
\hline$>100000$ & $1(6)$ & 5.43 & $0.95-31.0$ \\
\hline
\end{tabular}

${ }^{\star}$ No $=$ number of clinically diagnosed genital ulcerations; $(\%)=$ percentage of visits with clinically diagnosed ulcerations.

HOR = odds ratio; $\mathrm{CI}=$ confidence interval estimated with logistic regression for repeated measurements.

analysis, only the number of years of sexual activity and a history of prostitution remained independently and significantly associated with HSV-2 infection. Women with a history of prostitution had a 1.8-fold higher risk of HSV-2 infection than women without a history of prostitution. In addition, women who were sexually active for 20 years or more had an almost twofold higher risk of HSV-2 infection than women who were sexually active for less than 10 years. We found neither statistically significant confounding factors nor an interaction between history of prostitution and the number of years of sexual activity.

Overall, the number of recurrent genital ulcerations was low in HSV-2 positive women, even in immunosuppressed women (table 4). However, the recurrence of genital ulcerations was significantly higher in $\mathrm{HSV}-2$ infected women with CD 4 counts below 200 cells $\times 10^{6} / 1$ than in women with CD4 counts higher than 200 cells $\times 10^{6} / 1$. In the 194 women with available HIV-RNA measurements, recurrent HSV infections increased with increasing number of HIV-RNA copies, although not significantly. These results did not change after adjustment for co-infection with HSV-1.

Table 3 Risk factors associated with the presence of HSV-2 antibodies among 276 women registered in the European Women Study

\begin{tabular}{|c|c|c|c|c|c|c|c|}
\hline & \multirow[b]{2}{*}{ Prevalence (\%) } & \multicolumn{2}{|c|}{ Univariable } & \multirow[b]{2}{*}{$p$ Value } & \multicolumn{2}{|c|}{ Multivariable } & \multirow[b]{2}{*}{$p$ Value } \\
\hline & & $P R^{\star}$ & $95 \% C I^{\star}$ & & $P R^{\star}$ & $95 \% C I^{\star}$ & \\
\hline \multicolumn{8}{|l|}{ Mode of HIV transmission } \\
\hline Heterosexual intercourse & 38 & 1.00 & & & & & \\
\hline Injecting drug use & 60 & 1.61 & $1.21-2.09$ & & & & \\
\hline Other & 30 & 0.80 & $0.22-1.67$ & 0.006 & & & \\
\hline \multicolumn{8}{|l|}{ Geographical region } \\
\hline South & 35 & 1.00 & & & & & \\
\hline Central & 45 & 1.29 & $0.90-1.82$ & & & & \\
\hline North & 52 & 1.50 & $1.08-2.08$ & 0.047 & & & \\
\hline \multicolumn{8}{|l|}{ Age at sampling (years) } \\
\hline$<25$ & 32 & 1.00 & & & & & \\
\hline $25-29$ & 31 & 0.94 & $0.54-1.76$ & & & & \\
\hline $30-34$ & 43 & 1.33 & $0.82-2.38$ & & & & \\
\hline$>34$ & 56 & 1.72 & $1.09-3.03$ & 0.009 & & & \\
\hline History of STD & 55 & 1.64 & $1.25-2.16$ & $<0.001$ & & & \\
\hline History of prostitution & 81 & 2.13 & $1.60-2.67$ & $<0.001$ & 1.83 & $1.25-2.68$ & $<0.001$ \\
\hline \multicolumn{8}{|l|}{ Number of partners in lifetime } \\
\hline $0-5$ & 33 & 1.00 & & & & & \\
\hline $6-19$ & 39 & 1.19 & $0.83-1.71$ & & & & \\
\hline$\geqslant 20$ & 63 & 1.89 & $1.37-2.63$ & $<0.001$ & & & \\
\hline \multicolumn{8}{|l|}{ Years sexually active } \\
\hline$<10$ & 25 & 1.00 & & & 1.00 & & \\
\hline $10-19$ & 41 & 1.65 & $1.03-2.76$ & & 1.42 & $0.93-2.17$ & \\
\hline$\geqslant 20$ & 61 & 2.41 & $1.58-3.95$ & $<0.001$ & 1.99 & $1.28-3.10$ & $<0.001$ \\
\hline
\end{tabular}

$\star \mathrm{PR}=$ prevalence rate; $\mathrm{CI}=$ confidence interval estimated with log binomial regression analyses. 


\section{Discussion}

To our knowledge, this is the first study to describe risk factors for HSV-1 and HSV-2 antibodies in HIV infected women. The prevalence of HSV-1 and HSV-2 antibodies in the HIV infected women included in the present study was $76 \%$ and $42 \%$, respectively. The only independently associated risk factor of HSV-1 antibodies was geographic region. Our finding that the prevalence of HSV-1 antibodies is higher in southern Europe than in central and northern Europe is consistent with those of studies among various populations in several European countries, ranging from $60 \%$ among STD clinic attendees in Sweden up to $88 \%$ among women counselled in prenatal clinics in Italy. ${ }^{1}$ Geographic variation in the prevalence of HSV-1 antibodies might be explained by variation in socioeconomic factors during childhood, which we did not measure, such as family size and intimate family contact. Moreover, the presence HSV-1 antibodies was not related to sexual behaviour in this group of European HIV infected women. This lack of association is in contrast with the link found in recent studies between sexual behaviour and the presence of HSV-1 antibodies and with the suggestion that HSV-1 is of increasing importance as a cause of genital herpes. ${ }^{4521}$ Women in our cohort were probably infected early in life and already had antibodies for HSV -1 by the time they became sexually active. Our results suggested that HSV-1 infection reduces the risk for $\mathrm{HSV}-2$ infection, as was described by others. ${ }^{2} 322$

The prevalence of HSV-2 antibodies was strongly related to sexual behaviour. Women with a history of prostitution were at higher risk for HSV-2 infection than women without such a history. Furthermore, the prevalence increased with increasing number of sexually active years. Thus, in HIV infected women, the presence of HSV-2 antibodies may be used as a surrogate marker for sexual behaviour. These findings are consistent with those of studies among attendees of STD clinics ${ }^{23}$ and with population based surveys. ${ }^{25-27}$ Worldwide, there is some geographic variation in the prevalence of HSV-2 - for example, a higher prevalence in the United States and Africa. ${ }^{125} 2829$ However, we found no evidence for geographical variation within Western Europe.

Evidence was found for a relation between the recurrent genital ulcerations and markers of HIV disease progression. A decreasing CD4 count was associated with an increase in the recurrence of genital ulcerations in HSV-2 positive women. Recurrent genital ulcerations were more common in women with increased HIV-RNA levels, but the effect was not statistically significant. The recurrence of ulcerations increased with more advanced stages of HIV disease, as was found in a study among HIV infected prostitutes in Amsterdam. ${ }^{6}$ On the other hand, only a small proportion of HSV-2 infected women reported a history of genital herpes at the moment the blood sample used for HSV determination was obtained. This indicates that HSV-2 infection was present without symptoms in most of the HIV infected women included in this study. Since asymptomatic HSV shedding is (more) common in HIV positive than in HIV negative individuals, HIV infected women are at risk of transmitting HSV to their partners and neonates. ${ }^{30-32}$ Thus, their partners should use condoms to protect against transmission of HIV as well as of HSV. In HIV infected women of reproductive age, attention should be given to the possibility of vertical HSV transmission as well as HIV transmission.

Some limitations of this study should be noted. Firstly, a stored blood sample was available for only 276 of the 487 women included in the European women's study. Since women without a stored blood sample lived more often in northern Europe, it is likely that the prevalence of HSV-1 infection among all women included in the European women's study is lower. Risk factors of HSV-2 infection did not differ between women with and without a blood sample. Therefore, we assume that the results on HSV-2 prevalence in women with a stored blood sample are representative for the total group of women included in the European women's study. Secondly, the sensitivity of the EIA test we used was $95 \%$ for HSV-1 antibodies and varied between $98 \%$ and $99.7 \%$ for HSV-2 antibodies compared with western blots. ${ }^{13}{ }^{33}$ In HIV infected people, the test could yield a false negative for some cases, which may have led to an underestimation of the true prevalence. However, we retested sera with an intermediate extinction ratio with RIBA, which increased the sensitivity for both infections.

In conclusion, the prevalence of HSV-1 and HSV-2 antibodies is high in this group of HIV infected women. The use of condoms by their partners could prevent transmission of both HIV and HSV. Attention to the possibility of vertical HSV transmission is necessary along with measures to prevent vertical HIV transmission. The prevalence of HSV-1 antibodies differs by geographic region, being more common in women living in southern Europe than in women living in northern and central Europe. HSV-2 infection is strongly related, whereas HSV-1 infection appears unrelated to sexual behaviour in HIV infected women. We found evidence for a relation between the recurrence of genital ulcerations and markers for HIV disease progression in HIV infected women who are also HSV-2 positive.

Sponsored by the DG XII of the European Commission, the French National Agency for AIDS research (ANRS), and the Dutch AIDS Foundation (Stichting AIDS Fonds, project 2171).

We thank all women registered in the European study on the natural history of HIV infection in women for their ongoing participation, and Lucy Phillips, Ronald Geskus, and Arnaud Fontanet for their helpful comments and suggestions.

Contributors: $\mathrm{BvB}$ is the coordinator of the European Study on the Natural History of HIV Infection in Women. She performed the statistical analyses and prepared this manuscript; JS is head of the public health laboratory at which HSV tests were performed; AvdH is member of the steering committee of this study and she was involved in the design of the study; JM performed all the laboratory tests; MP is the project leader of the formed all the laboratory tests; MP is the project leader of the

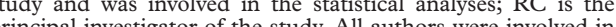
principal investigator of the study. All authors were involved in
the preparation of the final manuscript. There is no conflict of interest. 


\section{Appendix}

COLLABORATORS ON THE EUROPEAN STUDY ON THE NATURAL HISTORY OF HIV INFECTION IN WOMEN

Yolanda Pelgrom, Institute of Tropical Medicine, Antwerp, Belgium; Birgit Bak-Kvinesdal, Hvidover Hospital, Hvidover, Denmark; Jorma Paavonen, Hannele Savonius, Department of Obstetrics and Gynecology, University of Helsinki, Finland; Catherine Marimoutou, Groupe d'Epidémiologie Clinique du SIDA en Aquitaine, Bordeaux, France; Marie-Emmanuelle Mars, La Conception Hospital, Marseilles, France; Jean-Albert Gastaut, Dominique Sperandeo (steering committee), Saint-Marguerite Hospital, Marseilles, France; Christine Bergeron, CERBA, Cergy-Pontoise, France; Catherine Crenn-Hébert, Louis Mourier Hospital, Colombes, France; Françoise Meier, Louis Mourier Hospital, Colombes, France (steering committee); Paul Cesbron, Laënnec Hospital, Creil, France; Marie-Laure Babut, Henri Mondor Hospital, Créteil, France; Anne Odier, private practitioner, Paris, France; Jean-Dominique Poveda, Pasteur Institute, Paris, France; Alain Berrébi, La Grave Hospital, Toulouse, France; Anastasia Roumeliotou, Athens School of Public Health, Athens, Greece; José Fiore, Achiropita Lepera, Bari University, Bari, Italy; Alberto Matteelli, Anna Deltame, Brescia University, Brescia, Italy; Alberto Agarossi, Mario Conti, Daniele Federici, Sacco Hospital, Milan, Italy; Annarosa Del Mistro, Oncology Institute, Padova, Italy; Barbara Suligoi, Instituto Superiore di Sanità, Rome, Italy (steering committee); Karen Lindenburg, Joke Bax, Municipal Health Service, Amsterdam, The Netherlands; Elisabeth von der Lippe, Ullevål Hospital, Oslo, Norway; Lucia de Pinho, Coimbra Hospital, Coimbra, Portugal; Jorge Cardoso, Centro de Salude da Lapa, Lisbon, Portugal; Manuela Doroana, Santa Maria Hospital, Lisbon, Portugal; Soledad García Pérez, Sandoval Centre, Madrid, Spain; José María Peña, La Paz Hospital, Madrid, Spain; Jesús Grande, 12 de Octubre Hospital, Madrid, Spain; Elisa Pérez Cecilia, San Carlos Hospital, Madrid, Spain; Alberto Reche Rosado, Carlos Haya Hospital, Malaga, Spain; José Manuel Agud, Txagorritxu Hospital, Vitoria, Spain; Bo Anzén, Danderyd Hospital, Danderyd, Sweden (steering committee); Kristina Elfgren, Pehr Olof Pehrson, Huddinge University Hospital, Huddinge, Sweden; Pietro Vernazza, Katharina Keller, Kantonsspital, San Gallen, Switzerland.

1 Nahmias AJ, Lee FK, Beckman-Nahmias S. Seroepidemiological and -sociological patterns of herpes simplex virus infection in the world. Scand f Infect Dis Suppl 1990;69:19-36.

2 Bryson Y, Dillon M, Bernstein DI, et al. Risk of acquisition of genital herpes simplex virus type 2 in sex partners of persons with genital herpes: a prospective couple study. $\mathcal{F}$ persons with genital herpes:

3 Mertz GJ, Benedetti J, Ashley R, et al. Risk factors for the sexual transmission of genital herpes. Ann Intern Med 1992;116:197-202.

4 Dukers NHTM, Bruisten SM, de Wit JBF, et al. Strong decline in herpes simplex virus antibodies over time among young homosexual men is associated with changing sexual behavior. Am $\mathcal{F}$ Epidemiol 2001; (in press).

5 Ross JD, Smith IW, Elton RA. The epidemiology of herpes simplex types 1 and 2 infection of the genital tract in Edinburgh 1978-1991. Genitourin Med 1993;69:381-3.

6 Fennema JSA, van Ameijden EJC, Coutinho RA, et al. HIV, sexually transmitted diseases and gynaecologic disorders in women: increased risk for genital herpes and warts among HIV- infected prostitutes in Amsterdam. AIDS 1995;9: 1071-8.

7 Ghys PD, Diallo MO, Ettiegne-Traore V, et al. Genital ulcers associated with human immunodeficiency virusrelated immunosuppression in female sex workers in Abidjan, Ivory Coast. F Infect Dis 1995;172:1371-4.

8 Augenbraun M, Feldman J, Chirgwin K, et al. Increased genital shedding of herpes simplex virus type 2 in HIVseropositive women. Ann Intern Med 1995;123:845-7.
9 Breinig MK, Kingsley LA, Armstrong JA, et al. Epidemiology of genital herpes in Pittsburgh: serologic, sexual, and racial correlates of apparent and inapparent herpes simplex infections. F Infect Dis 1990;162:299-305.

10 Gibson JJ, Hornung CA, Alexander GR, et al. A crosssectional study of herpes simplex virus types 1 and 2 in college students: occurrence and determinants of infection. $\mathcal{F}$ Infect Dis 1990;162:306-12.

11 Koutsky LA, Stevens CE, Holmes KK, et al. Underdiagnosis of genital herpes by current clinical and viral-isolation procedures. N Engl f Med 1992;326:1533-9.

12 Van Benthem BHB, Prins M, Larsen C, et al. Sexually transmitted infections in European HIV-infected women: incidence in relation to time from infection. AIDS 2000;14:595-603.

13 Ashley RL, Wu L, Pickering JW, et al. Premarket evaluation of a commercial glycoprotein G-based enzyme immunoassay for herpes simplex virus type-specific antibodies. $\mathcal{F}$ Clin Microbiol 1998;36:294-5.

14 Alexander D, Dinello R, Ashley R, et al. Simultaneous use of derivates of glycoproteins $\mathrm{gBI}, \mathrm{gGI}, \mathrm{gD}$ and $\mathrm{gG} 2$ as antigens for a type-specific serological assay to diagnose prior infection with HSV-1 or HSV-2. 96th General Meeting of the American Society for Microbiology, New ing of the American

15 Van Doornum GJ, Slomka MJ, Buimer M, et al. Comparison of a monoclonal antibody-blocking enzyme-linked immunoassay and a strip immunoblot assay for identifying type-specific herpes simplex virus type 2 serological responses. Clin Diagn Lab Immunol 2000;7:641-4.

16 Zocchetti C, Consonni D, Bertazzi PA. Relationship between prevalence rate ratios and odds ratios in cros-sectional studies. Int f Epidemiol 1997;26:220-3.

17 Skov T, Deddens J, Petersen MR, et al. Prevalence proportion ratios: estimation and hypothesis testing. Int $\mathcal{f}$ Epidemiol 1998;27:91-5.

18 Davies HTO, Crombie IK, Tavakoli $M$. When can odds ratios mislead? BM7 1998;316:989-92.

19 SAS Institute. I. SAS/STAT Software: Changes enhancements through release 6.11. SAS Institute, 1996.

20 SAS Institute I. SAS/STAT Software: Changes enhancements through release 6.12. SAS Institute, 1996.

21 Cairo I, Fennema JSA, van den Hoek JAR. Trends in genital herpes simplex infections among STD clinic attenders in Amsterdam, 1991-1997. 13th Meeting of the International Society for Sexually Transmitted Diseases Research, July 11-14, 1999 , Denver Colorado, USA, 1999.

22 Conde-Glez CJ, Juarez-Figueroa L, Uribe-Salas F, et al. Analysis of herpes simplex virus 1 and 2 infection in women with high risk sexual behaviour in Mexico. Int $\mathcal{f}$ Epidemiol 1999;28:571-6.

23 Cowan FM, Johnson AM, Ashley R, et al. Antibody to herpes simplex virus type 2 as serological marker of sexual lifestyle in populations. BMF 1994;309:1325-9.

24 Van de Laar MJW, Termorshuizen F, Slomka MJ, et al. Prevalence and correlates of herpes simplex virus type 2 infection: evaluation of behavioural risk factors. Int $\mathcal{F}$ Epidemiol 1998;27:127-34.

25 Obasi A, Mosha F, Quigley M, et al. Antibody to herpes simplex virus type 2 as a marker of sexual risk behavior in rural Tanzania. F Infect Dis 1999;179:16-24.

26 Siegel D, Golden E, Washington AE, et al. Prevalence and correlates of herpes simplex infections. The populationbased AIDS in Multiethnic Neighborhoods Study. $¥ A M A$ 1992;268:1702-8.

27 Becker TM, Lee F, Daling JR, et al. Seroprevalence of and risk factors for antibodies to herpes simplex viruses, hepatitis $\mathrm{B}$, and hepatitis $\mathrm{C}$ among southwestern Hispanic and non-Hispanic white women. Sex Transm Dis 1996;23:13844

28 Johnson RE, Nahmias AJ, Magder LS, et al. A seroepidemiologic survey of the prevalence of herpes simplex virus type 12.

29 Fleming DT, McQuillan GM, Johnson RE, et al. Herpes simplex virus type 2 in the United States, 1976 to 1994 . $N$ simplex virus type 2 in the United

30 Mbopi KF, Gresenguet G, Mayaud P, et al. Genital herpes simplex virus type 2 shedding is increased in HIV-infected women in Africa. AIDS 1999;13:536-7.

31 Augenbraun M, Feldman J, Chirgwin K, et al. Increased genital shedding of herpes simplex virus type 2 in HIVseropositive women. Ann Intern Med 1995;123:845-7.

32 Schacker T, Zeh J, Hu HL, et al. Frequency of symptomatic and asymptomatic herpes simplex virus type 2 reactivations among human immunodeficiency virus-infected men. $f$ Infect Dis 1998;178:1616-22.

33 Groen J, Van Dijk G, Niesters HG, et al. Comparison of two enzyme-linked immunosorbent assays and one rapid immunoblot assay for detection of herpes simplex virus type 2 -specific antibodies in serum. F Clin Microbiol 1998;36:845-7. 